\title{
New approach of solving Euler deconvolution relation for the automatic interpretation of magnetic data
}

\author{
Nuraddeen Usman ${ }^{1,2, *}$, Khiruddin Abdullah ${ }^{1}$, Mohd Nawawi ${ }^{1}$, and Amin Esmail Khalil ${ }^{1}$ \\ ${ }^{1}$ School of Physics, Universiti Sains Malaysia, Pulau Pinang, Malaysia \\ ${ }^{2}$ Umaru Musa Yar'adua University, Katsina, Nigeria
}

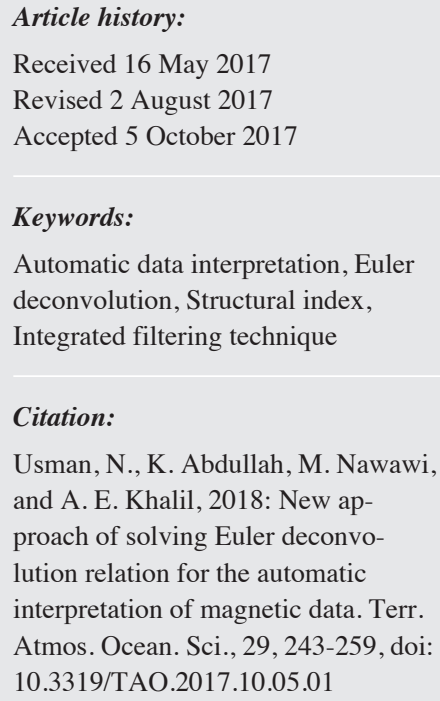

\begin{abstract}
The conventional Euler deconvolution has 5 unknown parameters to be solve which are the location of source $\left(x_{0}, y_{0}\right.$, and $\left.z_{0}\right)$, the background field and the structural index (SI). Among these 5 unknowns, the SI is to be manually selected by the interpreter. The manual input of SI into the Euler equation makes the technique to be semiautomated. A new technique based on Euler deconvolution that estimate background, horizontal coordinate $\left(x_{0}\right.$ and $\left.y_{0}\right)$, depth and structural index (SI) of gridded magnetic data is presented. The theoretical and field model study over magnetic sources demonstrates the ability of the method to solve for the source location and nature of the target, the technique does not depend on magnetic latitude. An integrated automated filter which is based on convolution window, SI deviation, regression error and analytic signal is prepared and used for selecting valid solution. Finally, the technique is applied to real magnetic data of Sebarang Jaya, the clustered depth solutions coincided with the high amplitude/values of analytic signal and these are the possible positions of the target being sought. The technique is fast means of magnetic data interpretation and easy to implement as it involves first order derivatives of the field.
\end{abstract}

\section{INTRODUCTION}

Geophysical techniques have been applied to investigate the subsurface of the earth in order to explore geological structures of economic interest (in most cases) in areas of environmental studies (Loke et al. 2013), hydrology, hydrocarbons, geochemical (Yang et al. 2015), engineering, geothermal studies (Khalil et al. 2017), geo-hazard assessment, and solid minerals (Arisona et al. 2016). With the aid of techniques used for inversion (Gerovska and Araúzo-Bravo 2003; Salem et al. 2008; Gerovska et al. 2010; Cooper 2015; Cooper and Whitehead 2016), it is possible to determine the horizontal and vertical positions of concealed metallic objects in the near vicinity of the earth's surface in addition to the delineation of deep-seated structures. With the aid of Euler homogeneity relation, magnetic method can be used to delineate the presence of metallic structures in the subsurface. The advantages of this method are its maximization to near surface weak magnetic signal produced by the buried

\footnotetext{
* Corresponding author

E-mail:nu14_phy055@student.usm.my
}

objects and its relative ease of operation.

The conventional Euler deconvolution (Thompson 1982; Reid et al. 1990; Ugalde and Morris 2010; Barbosa and Silva 2011; Oruç and Selim 2011; Chen et al. 2014) has 5 unknown parameters which are the location of source in $\mathrm{x}-, \mathrm{y}-$, and $\mathrm{z}$-directions $\left(x_{0}, y_{0}\right.$, and $\left.z_{0}\right)$, the background field and the structural index (SI). Among these 5 unknowns, the SI is to be manually selected by the interpreter/user. The manual input of SI into the Euler equation makes the technique to be semi-automated. An interpreter has to solve the equation using different SI and finally select the best set of solution. The interpreter is left with the decision that has the highest impact on the depth solutions: which SI should be chosen? Moreover, the geology of the earth is comprises of different structures which may not be fitted by a fixed SI. Hsu (2002) stated that the use of wrong SI can cause bias on depth estimate and scattered solution on target's locations.

Apart from conventional Euler deconvolution method, attempts were also made to automate the technique. Derivation based on Euler deconvolution and analytical signal 
(AS) equations have been presented in order to locate as well as approximate the SI of the source (Salem and Ravat 2003). This method involves the use of second order derivatives, it involves complex mathematical operations such as transformation of the total field and upward continuation. A method to calculate the depth, SI, dip and susceptibility contrast using vertical derivative of magnetic field and analytic signal is introduced in geophysical literature (Keating and Pilkington 2004). A method for estimating horizontal location and depth of the magnetic source based on tilt angle derivative has been developed (Salem et al. 2008). The SI is inferred from estimated source locations. The methodology involves the use of second order derivative. Stavrev (1997) have shown that Euler homogeneity equation can be solved using differential similarity transform (Gerovska and Araúzo-Bravo 2003; Gerovska et al. 2010). This method can deal with multiple interfering sources without prescribing SI, which permits simultaneous estimation of depth and SI of singular points.

One of the disadvantages of conventional Euler deconvolution is that the interpreter/user has to select SI manually. This property is a setback to one of the most important attribute of the technique which is fast means of interpreting large volume of data. Attempts made to estimate SI automatically surfer some drawbacks. Florio et al. (2006) have shown that AS is homogenous function hence, the application of Euler deconvolution on AS could lead to unwanted error. Moreover, the use of second order derivative amplifies noise in the data. The use of Differential Similarity Transform (DST) approach to solve for source location and SI is less implemented due to its higher complexity (Reid and Thurston 2014).

Unlike the past works, the present technique (introduced in this study) involves the use of first order derivatives, the inversion does not require analytic signal (AS) and it does not involve complex mathematical operations. It is simple to apply and the derivatives are computed directly from the total field grid. In the present work, the main objective is to estimate the position coordinates of magnetic source without prescribing the SI. With this methodology, the user/interpreter doesn't have to choose the structural index, it will be estimated automatically and this would increase the speed of operation. It is also intended to investigate the effect of inclination on the output of the new technique. A new integrated filter for selecting valid solutions automatically from the output of the inversion process is also presented.

\section{METHODOLOGY}

This section discusses the research methodology and approaches used in this study. It introduces the multiple linear regression technique and how it is used to solve 5 unknown parameters in the Euler deconvolution relation. This methodology involves computation of field's derivatives, inversion and filtering. Because of some advantages of analytic signal over anomalous/total field of magnetic sources, it is used as a guide for filtering the solution obtained from inversion process using the new approach. The accuracy assessment was carried out using synthetic models and field model. The procedure used in this section can be divided into three: computational method, numerical models and real data applications.

\subsection{Computational Method}

This section describes the application of MLR method of Euler deconvolution to solve for the position coordinates, nature of the source and background. The methodology used to validate the present technique such as theoretical and field models are described in this section. The procedure used to process a field data using the present technique is explained.

\subsubsection{Theory of the Method}

Euler deconvolution method is based on Euler's homogeneity relationship (John 1965); it was first initiated to solve 2D magnetic field by Thompson (1982). Euler deconvolution equation is normally used in order to find the source location $\left(x_{0}, y_{0}, z_{0}\right)$. Equation (1) forms the basis for the methodology used in this research and it is given as

$\left(x-x_{0}\right) \frac{\partial F}{\partial x}+\left(y-y_{0}\right) \frac{\partial F}{\partial y}+\left(z-z_{0}\right) \frac{\partial F}{\partial z}=N(B-F)$

where $x, y, z$ are the observation point coordinates; $x_{0}, y_{0}$, and $z_{0}$ are the source locations; $\frac{\partial F}{\partial x}, \frac{\partial F}{\partial y}, \frac{\partial F}{\partial z}$ are the potential derivatives; $N$ is the structural index; $B$ is the background of field $F$ (Thompson 1982).

\subsubsection{Multiple Linear Regression}

The Multiple Linear Regression (MLR) method has been extensively applied in statistics to establish relationships among multiple variables (more than two) by fitting a straight line to the observed data. MLR model can be expressed as (Levine et al. 2001):

$Y_{i}=\beta_{0}+\beta_{1} X_{1 i}+\beta_{2} X_{2 i}+\ldots+\beta_{k} X_{k i}+\varepsilon_{i}$

where $\beta_{0}$ is the intercept of $Y_{i} ; \beta_{1}, \beta_{2}$, and $\beta_{k}$ denote the slope of regression lines for each variable respectively, $\varepsilon_{i}$ is the regression error term and $Y_{i}$ is the dependent variable. To apply the MLR on 3D Euler deconvolution technique, Eq. (1) can be written in the following form Eq. (3) as MLR method: 
$x \frac{\partial F}{\partial x}+y \frac{\partial F}{\partial y}+z \frac{\partial F}{\partial z}=$

$N B+x_{0} \frac{\partial F}{\partial x}+y_{0} \frac{\partial F}{\partial y}+z_{0} \frac{\partial F}{\partial z}-N F$

By comparing Eqs. (2) and (3), we can say that: $Y_{i}=$ $x \frac{\partial F}{\partial x}+y \frac{\partial F}{\partial y}+z \frac{\partial F}{\partial z} ; \beta_{0}=N B ; \beta_{1}=x_{0} ; \beta_{2}=y_{0} ; \beta_{3}=z_{0} ; \beta_{4}=$ $N ; X_{1}=\partial F / \partial x ; X_{2}=\partial F / \partial y ; X_{3}=\partial F / \partial z$, and $X_{4}=-F$.

All $\beta_{\mathrm{i}} \mathrm{s}\left(\beta_{0}, \beta_{1}, \beta_{2}, \beta_{3}, \beta_{4}\right)$ are the coefficients (unknown) that need to be solved and all $X_{i}$ values are the independent variables, in which the values are known from the data (input). Assuming that Eq. (3) is linear, the equation could solve 5 unknowns which are horizontal positions $\left(x_{0}, y_{0}\right)$, depth $\left(z_{0}\right)$, SI $(N)$, and background $(B)$.

\subsubsection{Description of the Technique}

The pre-inversion processing commences with the interpolation/extrapolation to produce gridded data. The technique uses gridded data that consist of measured horizontal coordinates ( $x$ and $y$ ) and field $(F)$ of the observation point as input file to compute the first partial derivatives $\left(\frac{\partial F}{\partial x}, \frac{\partial F}{\partial y}, \frac{\partial F}{\partial z}\right)$ together with analytic signal for each data point. The computation of derivatives is done directly from the arrangement of data points (Breiner 1999). The derivatives required are horizontal derivatives (along $\mathrm{x}$ - and $\mathrm{y}$ directions) and vertical derivatives. The analytic signal of each data point is obtained from the derivative using the relation given in Eq. (4).

$$
|A S(x, y, z)|=\sqrt{\left(\frac{\partial F}{\partial x}\right)^{2}+\left(\frac{\partial F}{\partial y}\right)^{2}+\left(\frac{\partial F}{\partial z}\right)^{2}}
$$

The computed partial derivatives are then subjected to inversion. This technique is divided in to two main components: inversion and filtering applications.

\subsubsection{Data Inversion}

The derivatives are used to estimate for the source position coordinates $\left(x_{0}, y_{0}\right.$, and $\left.z_{0}\right)$, background $(B)$, and SI $(N)$ of source (as output) based on Eq. (3). In addition to the mentioned output parameters, others are regression error $\left(\varepsilon_{i}\right)$, analytic signal and centre of convolution window ( $x$ and $y$ ) which are very essential parameters for choosing reliable solution. The minimum acceptable window size is $3 \times 3$ grid points which correspond to 9 equations and 9 data points. Equation (3) can be solved using least square technique by prescribing the window size, which is the only subjective choice a user has to make. The window of these points shift along the grids at interval of one point until it finished a line of gridded data and then repeats the same process in the next line. It involves overlapping windows that estimate the un- known parameters for each window. After each successful inversion for a given window size, the user has the option to either start another session or stop the process. In effect, the user can repeat the process using different windows with each one saved in a different file.

For this methodology, odd numbers of window size were used for the inversion in order to use the centre of convolution window as criteria for filtering. Window that gives more solutions and produce clustered solutions (before filtering) is more preferable since a rigorous filter (introduced in this study) will be used to select reliable solutions. Window with less number of solutions can give few or no solution after filtering. Therefore, a window with more number of solutions, in addition to other considerations, is more preferable. The choice of window size was also based on the recommendation that the windows can be between $6 \times$ 6 and $20 \times 20$ grid points for shallow and deeper basement respectively (Reid et al. 1990). The deeper source can be differentiated from the shallower by the shape of anomaly. The window size determines the maximum depth of investigation. In general, the windows were made as small as possible to ensure that 2 or more anomalies were not inverted in the same window.

\subsubsection{Data Filtering}

Euler deconvolution method provides large number of possible solutions that need to be subjected to filtering in order to select the reliable solutions. Hence, the correct solutions need to be chosen and as discussed, there are techniques developed to supress the solutions which are not reliable. In this research, analytic signal was used as a guide to choose valid solution because of its so many advantages over other available filters. Some of the unique properties of AS includes its relationship with magnetization and earth field directions. It has been shown by Nabighian (1972) and Roest et al. (1992) that the AS is independent of the mentioned two directions. The filtering techniques used are divided into three stages:

(1) First stage filtering: The inversion program is built with filter that accepts solutions within the study area, other solutions outside the area under consideration are rejected. The program rejects negative depth solutions and accepts only positive depth values. The solution obtained is used by the integrated filter as an input.

(2) The second stage filtering (Table 1) consists of integrated filter which select solutions automatically based on centre of convolution window, SI deviation, regression error, and threshold of AS. Solutions outside convolution window width are more likely to be unreliable. The parameters used for this filtering depends on the model and are given as:

(a) Solutions outside the convolution window width are rejected. 
(b) Rejection based on deviation from integer value of structural index.

(c) Rejection of solution greater than certain value of regression error (in percentage).

(d) Analytic signal strength of the anomaly being greater than or equal to certain threshold, the solutions that falls within the set range should be retain otherwise rejected.

(3) Third stage (depends on the model) involves the use of traditional filtering techniques (FitzGerald et al. 2004; Melo et al. 2013) using Microsoft excel.

\subsection{Numerical Models}

Prior to the application of new Euler deconvolution technique to estimate depth, horizontal coordinates, and SI, its reliability was tested using sphere, finite and infinite boxes, and concrete wall models. The aim of theoretical modeling in this study is to provide the theoretical backing of the present technique. Also, the effect of inclination on this methodology has been tested using sphere model. The reliability of this technique was further tested using field model. The windows used for synthetic models were in the range of $5 \times 5$ grid points (very shallow source) to $13 \times$ 13 grid points (deeper source) in order to have enough curvature information to estimate the source's coordinate. The window sizes use to inversed the numerical models using the present technique are given in Table 1.

\subsubsection{Sphere Model}

Sphere model (Fig. 1) has been frequently used in geophysical literatures to test filters and performance assessment of depth estimation methods (Oruç 2010). A magnetic response due to a point dipole can be modelled in 3D Cartesian coordinate using the magnetic elements given by Salem et al. (2002). The model is designed to simulate response of a target with high magnetic field buried in an area with low background. The magnetization contrast was $1 \mathrm{~A} \mathrm{~m}^{-1}$, the depth to the centre and radius of the target were 1 and $0.5 \mathrm{~km}$ respectively. The horizontal coordinates in positive $\mathrm{x}$-directions was $12.4 \mathrm{~km}$ while that of y was $12.5 \mathrm{~km}$. The anomalous magnetic field of this model have been computed using different inclinations $\left(\mathrm{I}=0^{\circ}, 15^{\circ}, 30^{\circ}, 45^{\circ}, 60^{\circ}\right.$, $75^{\circ}$, and $90^{\circ}$ ). The analytic signal of the field (for $\mathrm{I}=45^{\circ}$ ) is computed and presented in Fig. 1. Other maps of analytic signal for different inclinations $\left(I=0^{\circ}, 15^{\circ}, 30^{\circ}, 60^{\circ}, 75^{\circ}\right.$, and $90^{\circ}$ ) are giving in the Appendix A. The computed derivatives were inversed using the window size of $9 \times 9$ grid points. The window size was selected in order to provide adequate curvature information to estimate the parameters of the source accurately. The window size constitutes odd numbers in order to provide a centre of the window which is very essential criterion for filtering. The filtering was carried out using the convolution window width of 9 unit, regression error and threshold of AS were $2 \%$ and $120 \mathrm{nT}$ $\mathrm{km}^{-1}$ respectively. The window sizes and filtering parameters used were given in Table 1.

\subsubsection{Finite Box Model}

The horizontal distance of this model (Fig. 2) is from 10 to $13 \mathrm{~km}$ in the positive $\mathrm{x}$-direction and 15 to $20 \mathrm{~km}$ in the positive y-direction. The depth to the top was $1 \mathrm{~km}$ and the depth to the bottom was $1.2 \mathrm{~km}$. This model is used to simulate the magnetic response of a buried concrete in igneous environment with magnetization of $-2.1 \mathrm{~A} \mathrm{~m}^{-1}$, the inclination used was $-5^{\circ}$ and the declination was $0^{\circ}$. The derivatives of the field were computed and inversed using the window size of $7 \times 7$ grid points. The choice of this window size is due to recommendation that the window size shall be as small as possible and window size $7 \times 7$ grid points produced good clustered solution. The parameters used for filtering of the solution obtained from inversion process using the present technique are given in Table 1.

\subsubsection{Infinite Box Model}

This model (Fig. 3) comprises of 4 long boxes with depth to the bottom at infinity use to simulate the magnetic response using the equation given by Bhattacharyya (1964) and it is also described in some literatures (Shamsipour et al. 2011, 2012; Abedi et al. 2013). The magnetization intensity of $\mathrm{B} 1$ and $\mathrm{B} 3$ models was $-2.1 \mathrm{~A} \mathrm{~m}^{-1}$ and each is $3 \mathrm{~km}$ wide in the east-west direction. $\mathrm{B} 1$ and $\mathrm{B} 3$ were $5 \mathrm{~km}$ long in the north south direction, and buried at $1 \mathrm{~km}$ depth. The other two features (B2 and B4), simulate similar structure but with different depth and magnetization contrast. The depth to the top and magnetization of the two bodies (B2 and B4) were $1.5 \mathrm{~km}$ and -2.8 $\mathrm{A} \mathrm{m}^{-1}$ respectively. In the present study, a plutonic rock is assumed as a source of magnetic intensity with inclination and declination of $-5^{\circ}$ and $0^{\circ}$ respectively. The data was inversed using the window size of $13 \times 13$ grid points and the result obtained was subjected to filtering. The window size was chosen by the considering the shape of the anomaly which is a suggestive of deeper source and the window size is connected with depth. Therefore, a bigger window would be more preparable. But still, the window size was made as small as possible as recommended (Reid et al. 1990) since the anomaly map indicated about 4 sources. The convolution window width was 13 unit and accepted SI deviation was 0.1 . The maximum accepted regression error and threshold of AS used were $10 \%$ and $220 \mathrm{nT} \mathrm{km}^{-1}$ respectively.

\subsubsection{Concrete Wall Model}

This model (Fig. 4) is simulated to estimate the magnetic response of the buried concrete wall model that was 
Table 1. Window size and filtering parameter of synthetic models.

\begin{tabular}{c|ccccc}
\hline model & Window size & Convolution window width & Deviation of structural index & Regression error $(\%)$ & Threshold of AS (nT km $\left.^{-1}\right)$ \\
\hline Sphere & $9 \times 9$ & 9 & 0 & 2 & 120 \\
Finite box & $7 \times 7$ & 7 & 0.1 & 1 & 30 \\
Infinite box & $13 \times 13$ & 13 & 0.1 & 10 & 220 \\
concrete wall & $5 \times 5$ & 5 & 0.4 & - & 14 \\
\hline
\end{tabular}

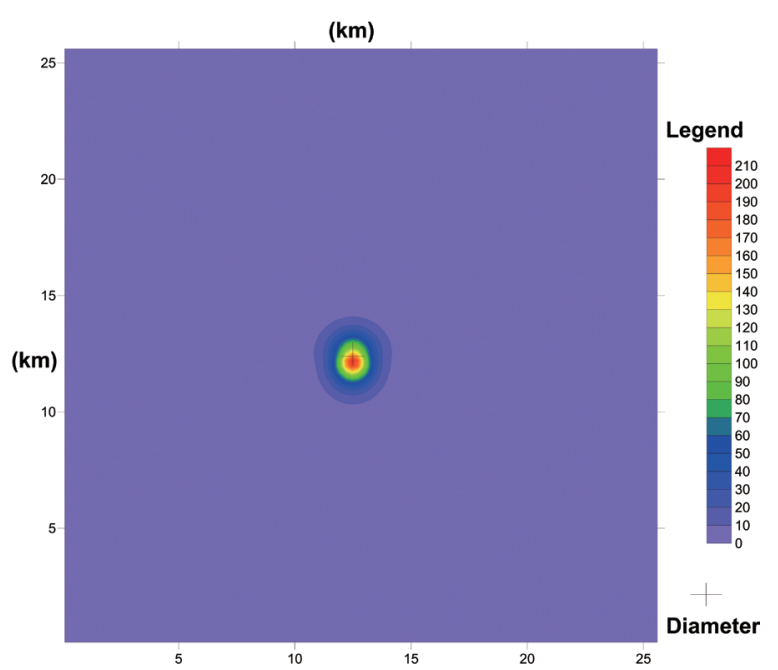

Fig. 1. AS $\left(\mathrm{nT} \mathrm{km}^{-1}\right)$ of sphere model $\left(\mathrm{I}=45^{\circ}\right)$.

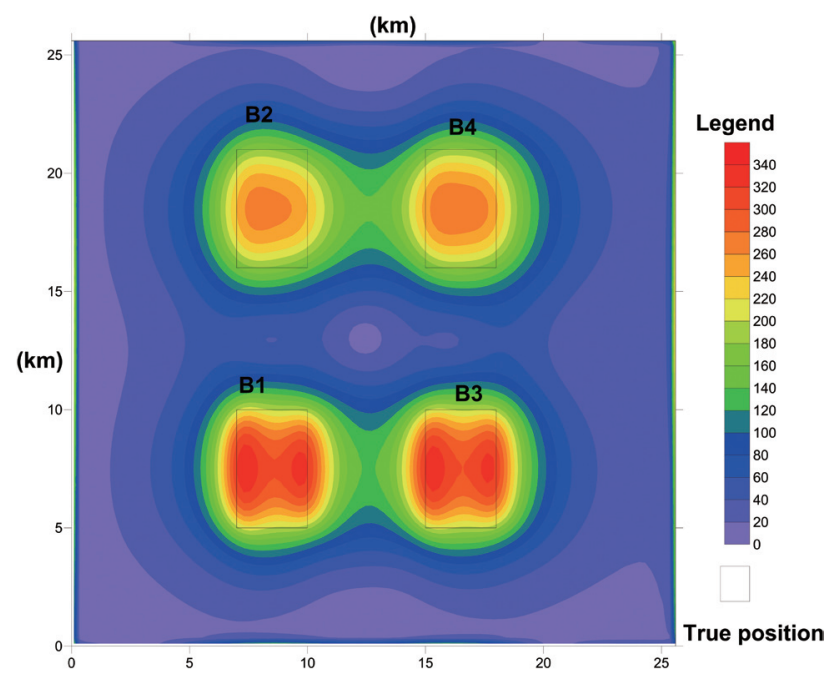

Fig. 3. AS $\left(\mathrm{nT} \mathrm{km}^{-1}\right)$ of infinite box model.

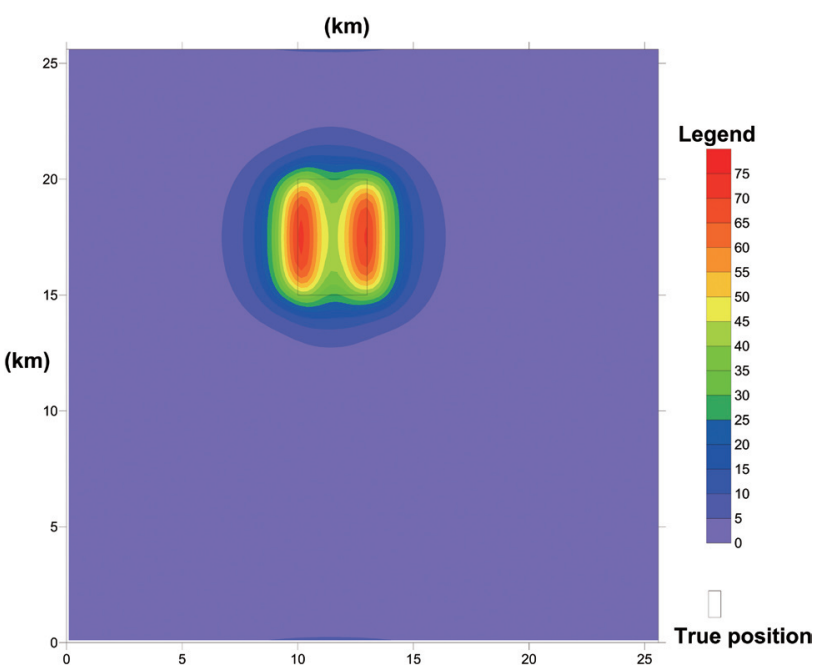

Fig. 2. AS (nT km-1) of finite box model.

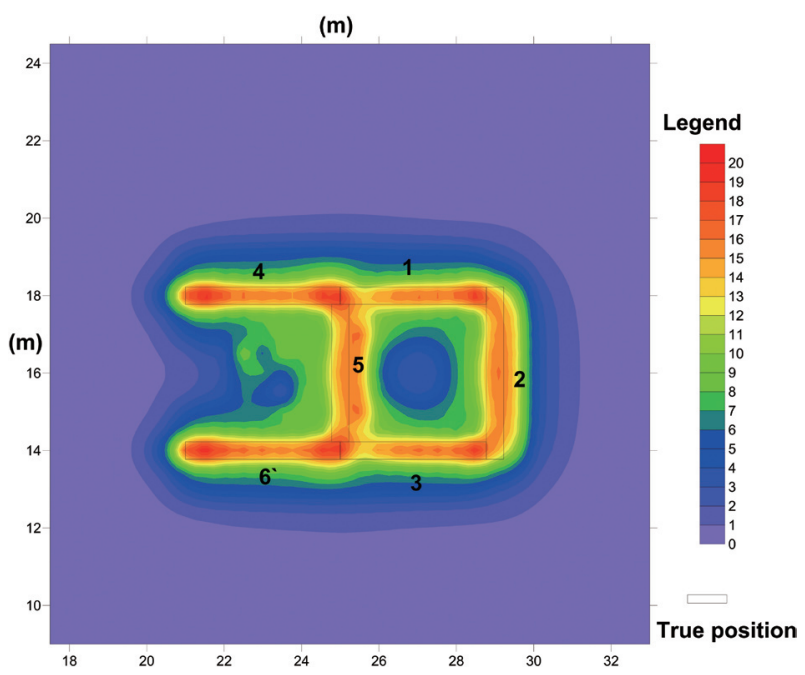

Fig. 4. AS $\left(\mathrm{nT} \mathrm{km}^{-1}\right)$ of concrete wall model. 
inspired from certain field model (Chambers et al. 2002). The inclination and declination of the model were $67.3^{\circ}$ and $-1^{\circ}$ respectively; the magnetization intensity was $0.1632 \mathrm{~A}$ $\mathrm{m}^{-1}$. The depth to top of the targets/objects was $0.6 \mathrm{~m}$ and oriented horizontally, the width and height of the objects were 0.45 and $0.4 \mathrm{~m}$ respectively, the objects were $4 \mathrm{~m}$ long. The effect of interference on the new technique introduced can be studied using such model, since it is made up of targets that are joined to each other. The derivatives are used as an input to the inversion and the window size used was 5 $\times 5$ grid points. The window size was selected based on the likelihood that so many sources (Fig. 4) caused the anomaly. The use of small window size would reduce the effect of the neighboring sources. Secondly, the anomaly seems to be caused by the shallow source and therefore it requires small window size. The convolution window width used was 5 unit, the accepted deviation of the SI was 0.4 and the threshold of AS used was $14 \mathrm{~km} \mathrm{nT}^{-1}$.

\subsection{Real Data}

The normal procedure for validation of a technique in geophysics is the use of synthetic, field model or an area with known detail geological information. Field model is used in order to justify the use of the technique in engineering and environmental applications (Ravat 1996; Salem et al. 2002; Marchetti et al. 2013). To effectively validate this technique, both synthetic and field models were used. The technique was finally applied to field data of a site under construction.

\subsubsection{Field Model}

The total magnetic field intensity is obtained from one of the two field models of Near Surface Geophysics Group of the geological society of London located at Leicester University. The data and other relevant information can be retrieved at http://www.nsgg.org.uk/test-sites/. It is located at latitude $52^{\circ} 36^{\prime} 27^{\prime \prime} \mathrm{N}$ and Longitude $1^{\circ} 5^{\prime} 12^{\prime}$ ' W Southmeads road, Oadby, Leicester. The site can be characterized as gentle hill-top with top layer of about $0.3 \mathrm{~m}$ thick. The Boulder clay material is distributed throughout the site; it is 16 - $18 \mathrm{~m}$ thick underlined by Liassic clays and limestone. This area was designed to simulate buried waste drums and other objects that are buried at depth range from $0.5-2 \mathrm{~m}$ filled with air or water. The parameters of each of the targets are shown in Table 2.

An important question that needs to be answered is that: does the present technique depends on magnetic latitude? To answer this question, reduction to the pole (RTP) technique was applied to the total magnetic field in order to assess the effect of inclination on the present technique. The inversion of the two data sets (total field and its RTP data) was carried out using window size $7 \times 7$ grid points. The data sets (total field and RTP) were filtered based on SI and analytic signal only for fair comparison. Negative SI values were rejected and threshold of AS used was $100 \mathrm{nT} \mathrm{m}^{-1}$. The inverted total field data (Euler solution) was re-subjected to filtering using the integrated filter and the parameters used were: the solutions are accepted within the maximum width of convolution centre of 7 units, the accepted SI deviation was 0.2 and threshold of AS was $100 \mathrm{nT} \mathrm{m}^{-1}$.

\subsubsection{Field Application (Sebarang Jaya, Parking Lot)}

The study area is located between geographical latitude $5.39525-5.39565^{\circ}$ and longitude $100.36585-100.36635^{\circ}$ at

Table 2. Description of the targets in the field model.

\begin{tabular}{c|cccccc}
\hline Target & Depth $(\mathbf{m})$ & Diameter $(\mathbf{m})$ & Height $(\mathbf{m})$ & shape & Fill & orientation \\
\hline 1 & 1 & 0.6 & 0.9 & Drum & Air & Vertical \\
2 & 1 & 0.6 & 0.9 & Drum & Water & Vertical \\
3 & 1 & 0.6 & 0.9 & Drum & Water & Vertical \\
4 & 1 & 0.6 & 0.9 & Drum & Air & Vertical \\
5 & 1 & 0.6 & 0.9 & Drum & Air & Vertical \\
6 & 0.5 & 0.6 & 0.9 & Drum & Air & Vertical \\
7 & 2 & 0.6 & 0.9 & Drum & Air & Vertical \\
8 & 1 & 0.6 & 0.9 & Drum & Air & Horizontal (E-W) \\
9 & 1 & 0.6 & 0.9 & Drum & Air & Horizontal (N-S) \\
10 & 1 & 0.6 & 0.9 & Drum & Air & Horizontal (NE-SW) \\
11 & 1 & 0.6 & 0.9 & Drum & Air & Horizontal (NE-SW) \\
12 & 1 & $0.6 \times 0.9$ & 0.9 & Granite boulder & - & Vertical (E-W) \\
13 & 1 & 0.6 & 0.01 & Steel plate & - & Horizontal \\
14 & 1 & 0.6 & 0.05 & Concrete slab & - & Horizontal \\
\hline
\end{tabular}


Sebarang Jaya (Parking Lot) in Butterworth (Penang), Malaysia. The geology of the Seberang Prai, Pulau Pinang was described by Hassan (1990). These areas (which include the study area) comprises of Quaternary geology which can be divided into three lithostratigraphic units; pleisteocene continental, Holecene, and terrestrial sediments. The sediments of Quaternary are thin along the hinter land and thick along western coastal area.

The construction items are made of materials with different shapes, which require different structural index (unknown) and the conventional Euler deconvolution technique (Thompson 1982; Reid et al. 1990; Mushayandebvu et al. 2004; Ugalde and Morris 2010; Barbosa and Silva 2011; Oruç and Selim 2011; Chen et al. 2014) require the use of fixed SI. The advantage of the new Euler deconvolution technique is that, it does not require the input of SI. There have been few publications in the literature concerning the application of Euler deconvolution in Engineering/ geotechnical characterization (Prezzi et al. 2005; Adelusi et al. 2013; Haile and Ayele 2014). Nordiana et al. (2012) stated that the essence of applying geophysical methods in geotechnical investigation is to minimize cost and time.

The magnetic survey was carried out using 2 sets of Proton precision magnetometer that serves as base and moving consoles. The base console was kept in an isolated area which is free from noise that might be caused as a result of moving or parked automobile and any other form of metallic material. The survey was carried out in grid form using the station interval of $2.5 \mathrm{~m}$. So many precautions had been taken in order to obtain accurate result: the readings were not taken during magnetic thunder storm, the readings were taken 3 times at each station, the operator did not wear any form of metallic material and after each 2 hrs the based magnetometer had been checked. The total magnetic field map of the study area is shown in Fig. 5. For the inversion of application site (Seberang Jaya) data, the window size used was $9 \times 9$ grid points. The filtering of the result was based on convolution window width which was 9 units, the maximum acceptable regression error was $20 \%$, SI deviation was 0.4 and AS was $50 \mathrm{nT} \mathrm{m}^{-1}$. The solutions that falls within the peak (high values) of AS positions were accepted, outside this portion/range, the solutions are rejected.

The nature of unknown underground structure can be obtained from the filtered Euler solution containing range of SI values $(0,1,2$, and 3$)$ shown in a map. Each feature is then examined based on the clustered solution of SI values. The SI that produced best solution clustering (located in areas with high values) is chosen as the value of that structure. The selected structural indices are then correlated with theoretical values of SI for simple shapes and the nature of the unknown structure is then interpreted.

\section{RESULT AND DISCUSSION}

This section presents the results obtained from forward modeling and inversion of both real and synthetic model using the introduced technique. The solutions obtained from filtering based on AS and other parameters are also included in this section.

\subsection{Sphere Model}

Considering the AS map in Fig. 1, a slight deviation of the target from the true position (depicted by + symbol) is observed despite the fact the effect of inclination is high at that inclination $\left(I=45^{\circ}\right)$. The slight deviation of the target from the true centre of dipole as depicted by analytic signal map is due to the effect of inclination. The solutions of the

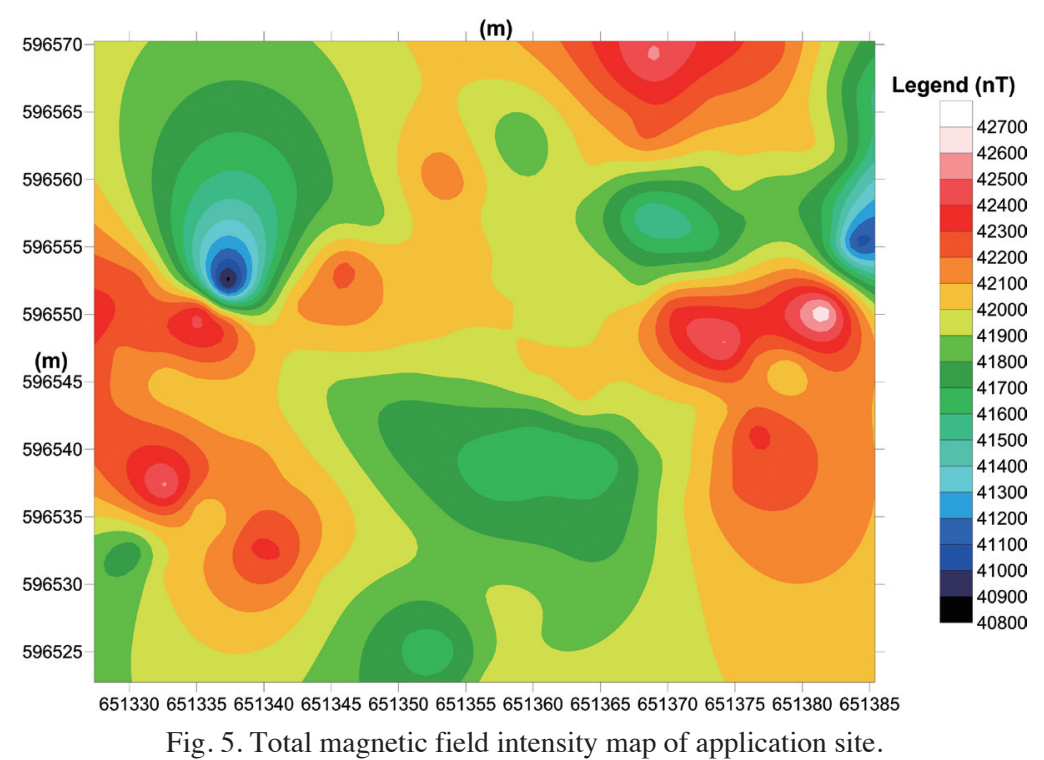

Fig. 5. Total magnetic field intensity map of application site. 
model $\left(\mathrm{I}=45^{\circ}\right)$ obtained using the present technique after filtering is super-imposed on AS (Fig. 6). Despite this effect, the present methodology has been able to locate the centre of the sphere accurately (Fig. 6). The maps of AS using different inclinations $\left(0^{\circ}, 15^{\circ}, 30^{\circ} 60^{\circ}, 75^{\circ}\right.$, and $\left.90^{\circ}\right)$ are given in the Appendix A. These maps indicated that the AS can be a good filter that can serve as an aid to choose the correct estimated positions from Eq. (3). For the same model (but different inclination: $0^{\circ}, 15^{\circ}, 30^{\circ}, 60^{\circ}, 75^{\circ}$, and $90^{\circ}$ ), the maps of depth solutions super-imposed on analytic signal are giving in the Appendix B. These maps indicated that the technique can locate a source without applying reduction to the pole technique.

The estimates of the unknown parameters using different inclinations are about the same (Table 3 ). At the pole ( $\mathrm{I}=$ $90^{\circ}$ ), the estimates of horizontal position, depth and SI show exact values. The estimated depth $\left(\mathrm{z}_{0}\right)$ shows very small deviation from the true value at the inclinations other than $90^{\circ}$. Therefore, the overall result shows good precision and this is an indication that the methodology can estimate the unknown parameters of the source with good accuracy and does not depend on inclination. In real geology, the sources are made up of so many dipoles and a lot of interference caused by the neighbouring bodies is expected. The presence of noise also affects the accuracy of estimation in real geology. However, moderate accuracy within the limit of acceptable error is expected. The theoretical validity of this method is therefore established. Theoretically, for isolated sphere, the present technique does not depend on inclination.

\subsection{Finite Box Model}

The estimated horizontal coordinate of $\mathrm{B}_{0}$ along $\mathrm{x}$ and $\mathrm{y}$ coordinates are perfectly estimated (Table 4 ). The minimum and maximum depth estimates are 1.02 and $1.11 \mathrm{~km}$ respectively (Fig. 7), the estimated SI varies from $0.91-1.09$. Table 4 shows the estimated mean depth value $(1.06 \mathrm{~km})$ and this value is about the same with the depth to the centre $(1.1 \mathrm{~km})$ of the target. Based on this model, the depth of investigation using this technique (introduced in this study) is depth to the centre. The estimated mean SI value of the target is approximately 1 . Unlike other models used in this research, box model gives wide range of SI (0 - 1.98). However, SI of about 1 provides good clustering (Fig. 7) to characterize the anomaly. The solutions of depth and horizontal positions obtained after the filtering are super imposed on AS and presented as a map (Fig. 7). It could be observed in Fig. 7 that the clustering formed at the 2 edges of the box and this is an indication of good precision of the present technique to estimate horizontal position, depth and SI of an isolated target.

\subsection{Infinite Box Model}

The horizontal coordinates (x,y) of both B1 and B2 located the target (Table 4) with good precision. The estimated $\mathrm{SI}$ of $\mathrm{B} 1$ and $\mathrm{B} 2$ is about 1 and this is an indication that this model is more of dike since the SI of box is not available in the literature. For B3, the horizontal coordinate along $\mathrm{x}$ direction is perfectly estimated. The maximum error for B4 in the estimation of $\mathrm{x}$ and $\mathrm{y}$ horizontal coordinates are 2 and $4 \%$ respectively. For the depth estimates, the depth to the top is over estimated. The depth estimate still considers accurate since the estimated depth is within the vicinity of the structure. The inversion of box model like target gives wide range of structural index. However, when the SI is between

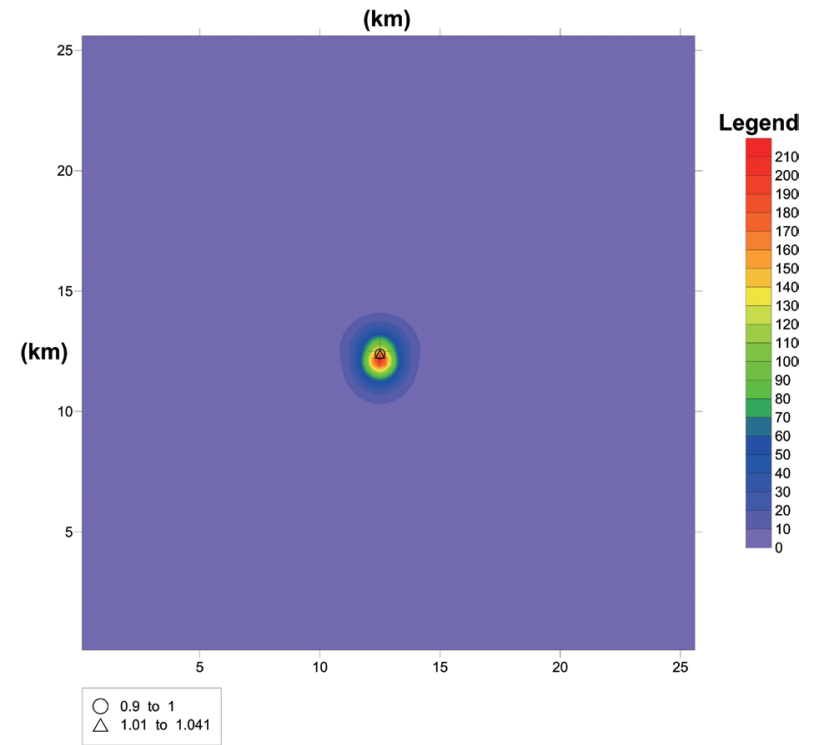

Fig. 6. Depth solutions of Sphere model $\left(I=45^{\circ}\right)$ super imposed on AS $\left(n T k^{-1}\right)$. 
Table 3. Euler solutions sphere model (number of solutions in the parenthesis). $\mathrm{N}_{0}$ is the estimated SI.

\begin{tabular}{c|ccccccc}
\hline $\mathbf{I}$ & $\mathbf{x}(\mathbf{k m})$ & $\mathbf{x}_{\mathbf{0}}(\mathbf{k m})$ & $\mathbf{y}(\mathbf{k m})$ & $\mathbf{y}_{\mathbf{0}}(\mathbf{k m})$ & $\mathbf{z}(\mathbf{k m})$ & $\mathbf{z}_{\mathbf{0}}(\mathbf{k m})$ & $\mathbf{N}_{\mathbf{0}}$ \\
\hline $0^{\circ}(19)$ & 12.5 & 12.5 & 12.4 & 12.4 & 1 & $1.01 \pm 0.01$ & 3 \\
$15^{\circ}(26)$ & 12.5 & 12.5 & 12.4 & 12.4 & 1 & $1.01 \pm 0.01$ & 3 \\
$30^{\circ}(18)$ & 12.5 & 12.5 & 12.4 & 12.4 & 1 & $1.01 \pm 0.1$ & 3 \\
$45^{\circ}(13)$ & 12.5 & 12.5 & 12.4 & 12.4 & 1 & $1.005 \pm 0.005$ & 3 \\
$60^{\circ}(24)$ & 12.5 & 12.5 & 12.4 & 12.4 & 1 & $1.01 \pm 0.01$ & 3 \\
$75^{\circ}(12)$ & 12.5 & 12.5 & 12.4 & 12.4 & 1 & $1.01 \pm 0.01$ & 3 \\
$90^{\circ}(16)$ & 12.5 & 12.5 & 12.4 & 12.4 & 1 & 1 & 3 \\
\hline
\end{tabular}

Table 4. Synthetic model result (number of solutions in the parenthesis) after filtering.

\begin{tabular}{|c|c|c|c|c|c|c|c|c|}
\hline Structure & $\mathbf{x}$ & $\mathbf{x}_{0}$ & $\mathbf{y}$ & $\mathbf{y}_{\mathbf{0}}$ & $\mathbf{z}$ & $\mathbf{z}_{0}$ & $\mathbf{N}$ & $\mathbf{N}_{\mathrm{o}}$ \\
\hline \multicolumn{9}{|c|}{ Finite box model } \\
\hline B0 (44) km & $10-13$ & $10-13$ & $15-20$ & $15-20$ & $1-1.2$ & $1.06 \pm 0.03$ & - & $0.995 \pm 0.06$ \\
\hline \multicolumn{9}{|c|}{ Infinite box model } \\
\hline $\mathrm{B} 1(125) \mathrm{km}$ & $7-10$ & $7.1-10$ & $5-10$ & $5.3-10$ & 1 to $\infty$ & $1.72 \pm 0.44$ & - & $1 \pm 0.09$ \\
\hline B2 (112) km & $7-10$ & $7.1-9.9$ & $16-21$ & $16.5-20.7$ & 1.5 to $\infty$ & $1.87 \pm 0.16$ & - & $1 \pm 0.09$ \\
\hline B3 (134) km & $15-18$ & $15-18$ & $5-10$ & $5-9.9$ & 1 to $\infty$ & $1.69 \pm 0.45$ & - & $1 \pm 0.9$ \\
\hline B4 (123) km & $15-18$ & $14.7-17.9$ & $16-21$ & $16.7-20.6$ & 1.5 to $\infty$ & $1.905 \pm 0.215$ & - & $1 \pm 0.09$ \\
\hline \multicolumn{9}{|c|}{ Concrete wall model } \\
\hline Concrete wall (97) m & $21-28.775$ & $20.9-29.2$ & $13.775-18.225$ & $13.8-18.2$ & 0.6 & $0.59 \pm 0.15$ & - & $1.21 \pm 0.46$ \\
\hline
\end{tabular}

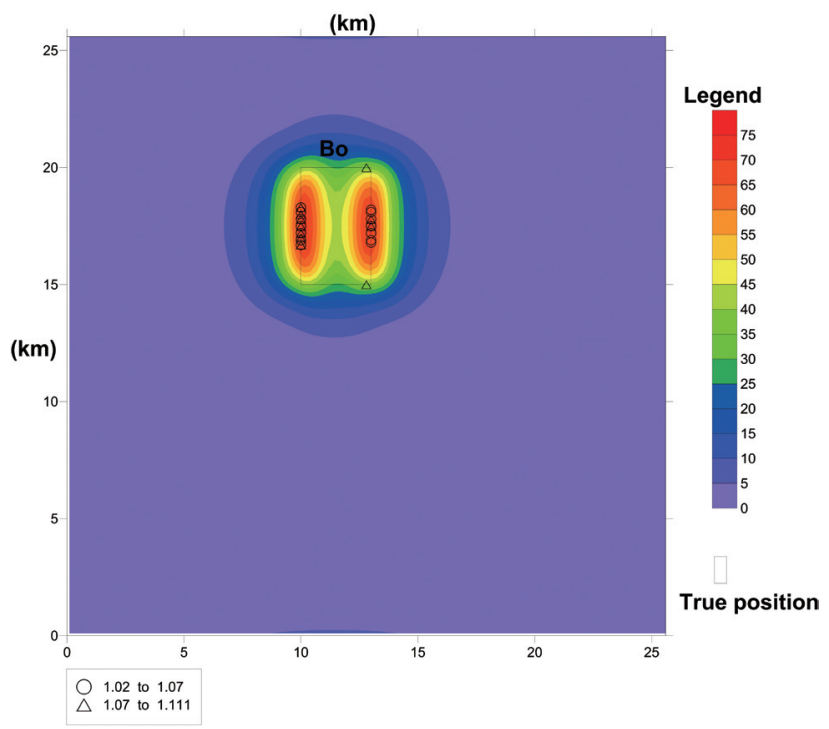

Fig. 7. Depth solution of finite box model super imposed on AS (nT km-1). 
0.9 and 1.1 (Table 4), better clustered solution is obtained (Fig. 8). The present methodology permitted accurate estimation of a box like theoretical target, despite its complex nature. The estimated positions coordinates of this model (after the filtering) are super-imposed on AS and presented in Fig. 8. It could be observed from Fig. 8, that the vertical edges/border of the 4 boxes are well delineated with good clustering of solutions. However, the horizontal border of the box is not resolved and this effect has to do with the direction of the field. The assumed magnetic north and the horizontal distance have the same direction. The vertices of B1 and B3 are well delineated to distinguish the box from the dike structure. From this study, it is observed that for box like geological structure, the technique detect position of the target at the boarder/edge.

\subsection{Concrete Wall Model}

The estimated model parameters have low error when compared with the true parameters especially on position estimates (Table 4$)$. The mean depth value $(0.59 \mathrm{~m})$ obtained coincided with depth to the top of the target $(0.6 \mathrm{~m})$. For the structural index, the estimated mean value of concrete wall model in Table 4 (1.21) indicated that the target is about 1 (as also indicated by infinite and finite box models). The estimated depth values are super imposed on AS and presented in Fig. 9. In Fig. 9, all the depth solutions are located at the edges of the targets, the corner positions are well depicted by clustered solutions. However, the minimum and maximum values of depth are 0.14 and $0.86 \mathrm{~m}$ respectively. This result has demonstrated that the present technique can be used to delineate structures in geotechnical investigation with reliable position estimates despite the effect of inter-

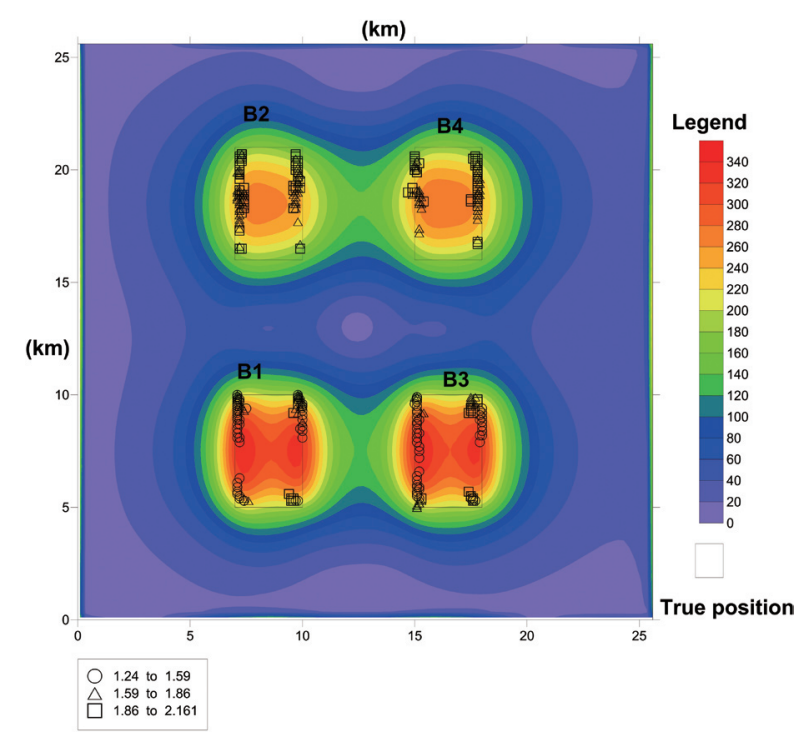

Fig. 8. Depth solution of finite box model super imposed on AS $\left.(\mathrm{nT} \mathrm{km})^{-1}\right)$. ference. The effect of interference is visible on depth and SI estimates, moderate deviations are observed (Table 4). The effectiveness of filtering technique used in this research assisted in the selection of more reliable solution following the location of AS values above the threshold value. Hence, the theoretical basis of the present technique is established using model study.

\subsection{Field Model}

It can be observed from total field and its RTP maps (Figs. 10 and 11) that the targets are more positioned at the centre in RTP than the total field map. The inversion result of total field and RTP data are shown in Tables 5 and 6 , respectively. It can be deduced that the two data sets have nearly the same solution. The highest difference between the two solutions was $0.8 \mathrm{~m}\left(\mathrm{y}_{0}\right.$ in target 2$)$ while in some parameters of the target $\left(\mathrm{x}_{0}\right.$ in target 6 and 11), the estimated values are the same in both the two data sets (total field and RTP). This implies that the technique is irrespective of the magnetic inclination, therefore the present technique does not require RTP operation before inversion.

With the filtering using 4 criteria applied to the inverted data of total magnetic field, no significance difference is observed (Table 7) compare to RTP and total field result that were filtered using 2 criteria (SI and AS). Although the filtering parameters used were selected in order to allow more solution to be accepted, this further, confirm the robustness of using analytic signal threshold for filtering. When the filtering parameters used are very strict, more precise estimates are obtained but vital information would be lost, especially from targets with few numbers of solutions. This is what happened to target 3 and 7 (Figs. 10 and 12), the solutions

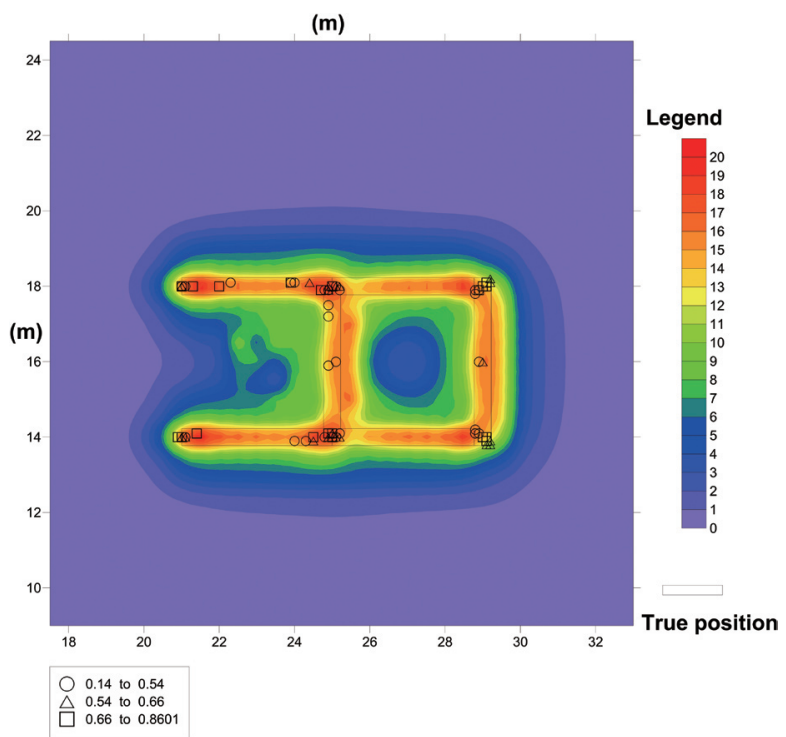

Fig. 9. Depth solution of concrete wall model super imposed on $\mathrm{AS}\left(\mathrm{nT} \mathrm{km}^{-1}\right)$. 


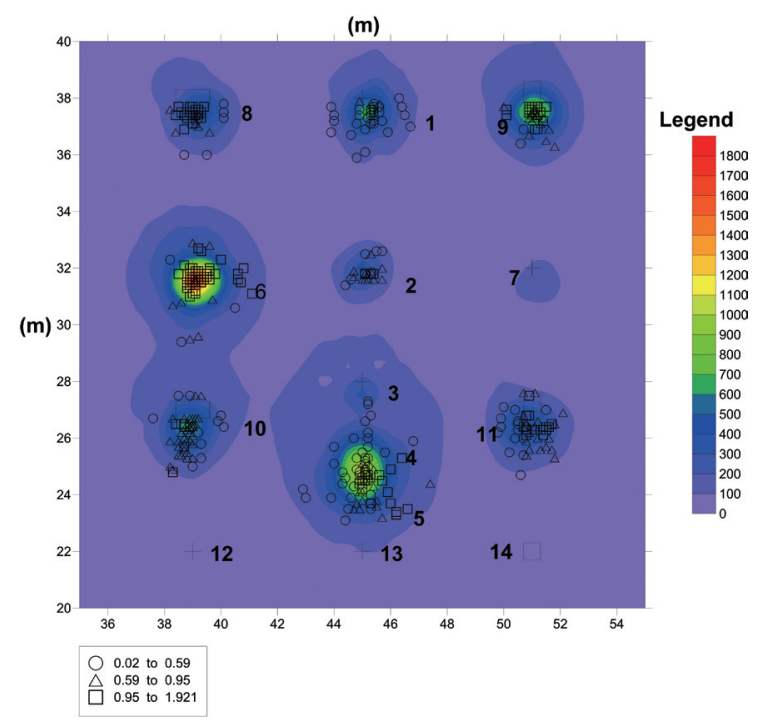

Fig. 10. Depth solution super imposed on AS $\left(\mathrm{nT} \mathrm{m}^{-1}\right)$ of total field of the field model.

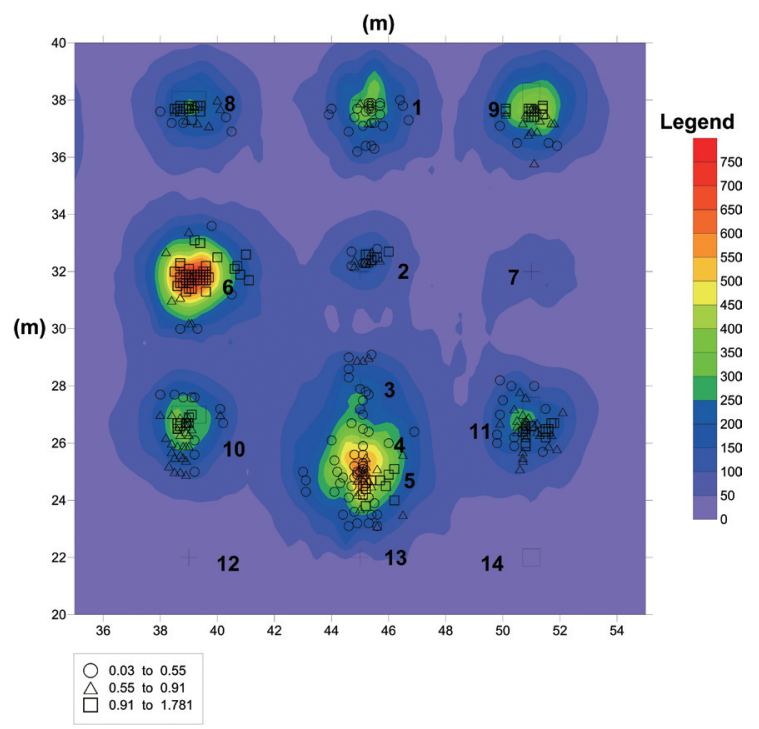

Fig. 11. Depth solution super imposed on AS $\left(\mathrm{nT} \mathrm{m}^{-1}\right)$ of reduction to the pole of the field model.

Table 5. Total field of field model inversion result, window size 7 (number of solutions in the parenthesis).

\begin{tabular}{c|cccccccc}
\hline Target & $\mathbf{x}(\mathbf{m})$ & $\mathbf{x}_{\mathbf{0}}(\mathbf{m})$ & $\mathbf{y}(\mathbf{m})$ & $\mathbf{y}_{\mathbf{0}}(\mathbf{m})$ & $\mathbf{z}(\mathbf{m})$ & $\mathbf{z}_{\mathbf{0}}(\mathbf{m})$ & $\mathbf{N}$ & $\mathbf{N}_{\mathbf{0}}$ \\
\hline $1(32)$ & $44.7-45.3$ & $43.9-46.5$ & $37.7-38.3$ & $36.7-38$ & 1 & $0.425 \pm 0.195$ & - & $0.48 \pm 0.4$ \\
$2(24)$ & $44.7-45.3$ & $44.4-45.7$ & $31.7-32.3$ & $31.4-32.6$ & 1 & $0.53 \pm 0.51$ & - & $0.79 \pm 0.69$ \\
3 & $38.7-39.3$ & - & $27.7-28.3$ & - & 1 & - & - & - \\
4 & $4.7-5.3$ & - & $25.7-26.3$ & - & 1 & - & - & - \\
$5(62)$ & $44.7-45.3$ & $44-46.6$ & $24.7-25.3$ & $23.1-25.5$ & 1 & $1.055 \pm 0.865$ & - & $0.995 \pm 0.985$ \\
$6(69)$ & $38.7-39.3$ & $38.2-41.1$ & $31.7-32.3$ & $30.6-32.9$ & 0.5 & $1.14 \pm 0.69$ & - & $1.78 \pm 1.65$ \\
7 & $50.7-51.3$ & - & $31.7-32.3$ & - & 2 & - & - & - \\
$8(38)$ & $38.55-39.45$ & $38.2-40.1$ & $37.55-38.45$ & $36.8-37.8$ & 1 & $0.82 \pm 0.65$ & - & $1.05 \pm 0.91$ \\
$9(39)$ & $50.7-51.3$ & $50-51.6$ & $37.7-38.3$ & $36.9-37.7$ & 1 & $0.925 \pm 0.525$ & - & $1.25 \pm 0.81$ \\
$10(39)$ & $38.55-39.45$ & $37.6-39.3$ & $26.7-27.3$ & $25.8-27.5$ & 1 & $0.64 \pm 0.49$ & - & $0.715 \pm 0.685$ \\
$11(51)$ & $50.7-51.3$ & $49.8-52.1$ & $26.55-27.45$ & $25.4-27.6$ & 1 & $0.65 \pm 0.48$ & - & $0.86 \pm 0.61$ \\
\hline
\end{tabular}

Table 6. Reduction to the pole of field model inversion result, window size 7 (number of solutions in the parenthesis).

\begin{tabular}{c|cccccccc}
\hline Target & $\mathbf{x}(\mathbf{m})$ & $\mathbf{x}_{\mathbf{0}}(\mathbf{m})$ & $\mathbf{y}(\mathbf{m})$ & $\mathbf{y}_{\mathbf{0}}(\mathbf{m})$ & $\mathbf{z}(\mathbf{m})$ & $\mathbf{z}_{\mathbf{0}}(\mathbf{m})$ & $\mathbf{N}$ & $\mathbf{N}_{\mathbf{0}}$ \\
\hline $1(28)$ & $44.7-45.3$ & $44-46.5$ & $37.7-38.3$ & $36.4-38$ & 1 & $0.39 \pm 0.17$ & - & $0.44 \pm 0.4$ \\
$2(14)$ & $44.7-45.3$ & $44.7-45.4$ & $31.7-32.3$ & $32.2-32.4$ & 1 & $0.705 \pm 0.435$ & - & $0.84 \pm 0.67$ \\
$3(2)$ & $38.7-39.3$ & $45.1-45.3$ & $27.7-28.3$ & $28.9-29$ & 1 & $0.79 \pm 0.1$ & - & $0.04 \pm 0.03$ \\
4 & $4.7-5.3$ & - & $25.7-26.3$ & - & 1 & - & - & - \\
$5(43)$ & $44.7-45.3$ & $44.1-46.5$ & $24.7-25.3$ & $23.5-25.6$ & 1 & $0.775 \pm 0.535$ & - & $0.67 \pm 0.67$ \\
$6(72)$ & $38.7-39.3$ & $38.2-41.1$ & $31.7-32.3$ & $30-33.4$ & 0.5 & $1.1 \pm 0.68$ & - & $1.56 \pm 1.5$ \\
7 & $50.7-51.3$ & - & $31.7-32.3$ & - & 2 & - & - & - \\
$8(31)$ & $38.55-39.45$ & $38.4-40.5$ & $37.55-38.45$ & $36.9-38$ & 1 & $0.7 \pm 0.5$ & - & $0.815 \pm 0.765$ \\
9 & $50.7-51.3$ & - & $37.7-38.3$ & - & 1 & - & - & - \\
$10(41)$ & $38.55-39.45$ & $38-39.2$ & $26.7-27.3$ & $25.6-27$ & 1 & $0.855 \pm 0.365$ & - & $0.94 \pm 0.67$ \\
$11(57)$ & $50.7-51.3$ & $49.8-52.1$ & $26.55-27.45$ & $25.1-28.2$ & 1 & $0.705 \pm 0.575$ & - & $0.72 \pm 0.72$ \\
\hline
\end{tabular}


Table 7. Total field of field model inversion result, window size 7 (number of solutions in the parenthesis).

\begin{tabular}{c|cccccccc}
\hline Target & $\mathbf{x}(\mathbf{m})$ & $\mathbf{x}_{\mathbf{0}}(\mathbf{m})$ & $\mathbf{y}(\mathbf{m})$ & $\mathbf{y}_{\mathbf{0}}(\mathbf{m})$ & $\mathbf{z}(\mathbf{m})$ & $\mathbf{z}_{\mathbf{0}}(\mathbf{m})$ & $\mathbf{N}$ & $\mathbf{N}_{\mathbf{0}}$ \\
\hline $1(9)$ & $44.7-45.3$ & $44-46.5$ & $37.7-38.3$ & $37.2-37.9$ & 1 & $0.425 \pm 0.195$ & - & $0.48 \pm 0.4$ \\
$2(12)$ & $44.7-45.3$ & $44.4-45.7$ & $31.7-32.3$ & $31.4-32.6$ & 1 & $0.435 \pm 0.415$ & - & $0.645 \pm 0.545$ \\
3 & $38.7-39.3$ & - & $27.7-28.3$ & - & 1 & - & - & - \\
4 & $4.7-5.3$ & - & $25.7-26.3$ & - & 1 & - & - & - \\
$5(11)$ & $44.7-45.3$ & $45-45.6$ & $24.7-25.3$ & $24.7-25.5$ & 1 & $1.155 \pm 0.765$ & - & $0.995 \pm 0.985$ \\
$6(34)$ & $38.7-39.3$ & $38.6-40.8$ & $31.7-32.3$ & $30.6-32.7$ & 0.5 & $1.14 \pm 0.69$ & - & $1.47 \pm 1.34$ \\
7 & $50.7-51.3$ & - & $31.7-32.3$ & - & 2 & - & - & - \\
$8(14)$ & $38.55-39.45$ & $38.2-40.1$ & $37.55-38.45$ & $36.8-37.7$ & 1 & $0.82 \pm 0.65$ & - & $1.05 \pm 0.91$ \\
$9(16)$ & $50.7-51.3$ & $50-51.5$ & $37.7-38.3$ & $36.5-37.7$ & 1 & $0.815 \pm 0.125$ & - & $1.01 \pm 0.15$ \\
$10(18)$ & $38.55-39.45$ & $37.6-39.3$ & $26.7-27.3$ & $25.7-27.5$ & 1 & $0.565 \pm 0.415$ & - & $0.595 \pm 0.565$ \\
$11(17)$ & $50.7-51.3$ & $50.6-51.8$ & $26.55-27.45$ & $24.7-27.5$ & 1 & $0.755 \pm+0.325$ & - & $0.63 \pm 0.53$ \\
\hline
\end{tabular}

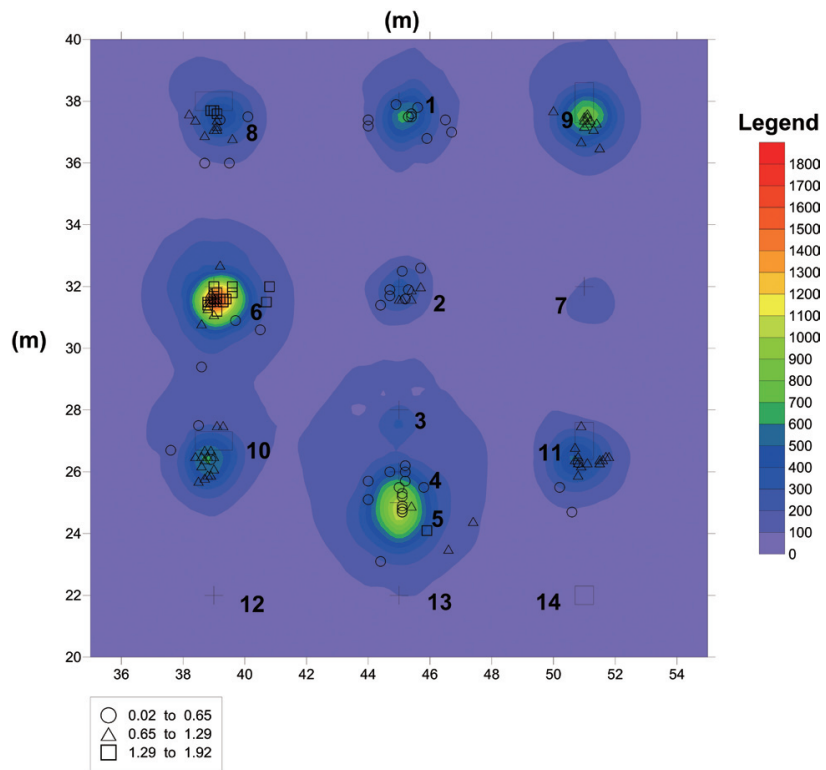

Fig. 12. Depth solution super imposed on AS $\left(\mathrm{nT} \mathrm{m}^{-1}\right)$ of total field of the field model (after filtering).

are rejected during the filtering process. The technique detected most of the position of the targets with good magnetization contrast (Fig. 12). Also, Table 7 has indicated that the technique is very effective in estimating the horizontal position as most of the estimated values are about the same with the true values. However, targets 12, 13, and 14 that have poor magnetization contrast are not detected by the present technique. This implies that for this technique to estimate the unknown parameters of the target [using Eq. (3)], the magnetization contrast must be sufficient. The depth solutions obtained vary from $0.02-1.92 \mathrm{~m}$. The depth solutions of the two targets are over estimated (target 5 and 6 ) while most of the estimated depth of the targets are underestimated (target $1,2,8,9,10$, and 11). Theoretically, the SI of some simple models is from zero to three, however in real geology more complexity is expected. More sources and complex shapes with no theoretical SI values are present in such a medium. The estimated SI values of this model vary from $0-2$ and the average is approximately 1 (Table 7).

\subsection{Real Data Application}

The depth solutions obtained after the filtering process are super-imposed on analytic signal map and presented in Fig. 13. Based on the depth and horizontal solutions obtained, the concrete pillars containing the iron are located at the position indicated by high and moderate value of the analytic signal with the maximum depth of $9.401 \mathrm{~m}$. 
Considering Fig. 13, there are about 10 peaks (numbered 1 to 10$)$ indicated by analytic signal. At most positions $(1,2$, $3,4,5,6,8)$, the estimated depths form considerable clustering which is an indicative of the presence of structure(s) beneath the surface. In addition to clustered solutions, some scattered solutions (7 and 10) are present. The scattered solutions are not reliable and are normally not considered while making the interpretation. These clustered sources are interpreted as possible position of concrete pillars containing the iron material. Earth is heterogeneous in nature; therefore some of the shallow solutions are due to sources such as utility items and other local features available in the area. It could be observed from the theoretical and field model studies that the source coordinates are estimated with reasonable accuracy.

The non-integer value of structural index using different techniques has been successfully applied in geophysical data interpretation (Thompson 1982; Reid et al. 1990; Salem et al. 2008; Tedla et al. 2011). These structural indices (non-integers) are interpreted as transitional points between sources of different shapes. The theoretical concept of structural index applies to simple shape, however, this assumption does not preclude the use of Euler deconvolution technique to real geology where the shapes of structures are complex. By implication, the use of non-integer structural indices should not be downgraded so long as it can be used as an aid to construct a model of the subsurface geology. To further address such problems, the source body critical points were identified and used as suggested by Reid and Thurston (2014). This is achieved by using the peak of AS to locate and accept solutions only at such critical points.

Figure 14 shows a map of SI values super-imposed on AS depicting various structural indices, this is in confor-

$(\mathrm{m})$

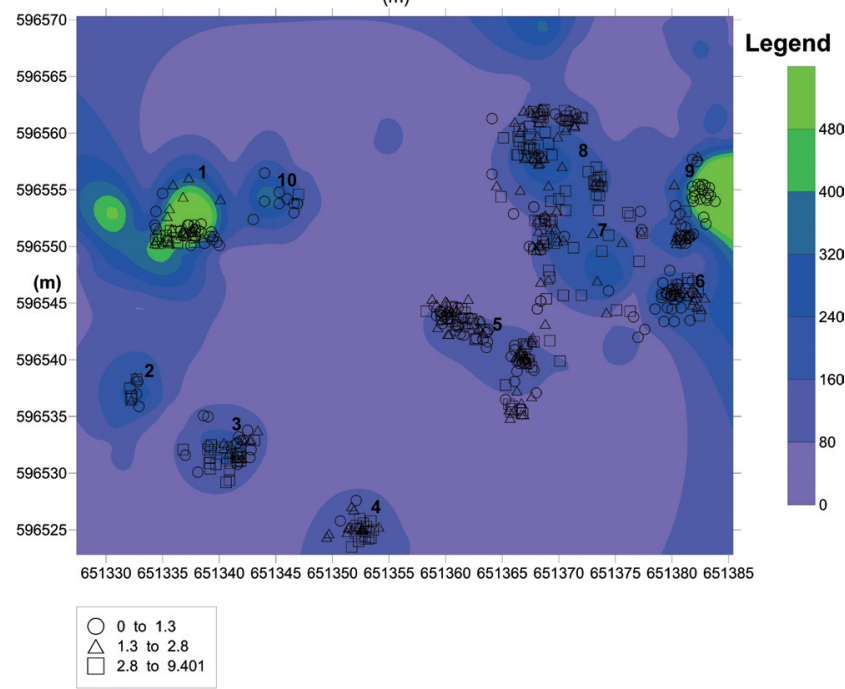

Fig. 13. Depth solutions (application site) super imposed on AS $\left(\mathrm{nT} \mathrm{m} \mathrm{m}^{-1}\right)$. mity with explanation made by Reid et al. (1990) that the real data is likely contains anomalies of sources with different SI. Each range represents one of the four theoretical indices $(0,1,2$, and 3$)$. Unlike the conventional technique which produced 4 or more maps using different structural indices, the present technique produced single map that accommodate all the indices. The SI of zero is interpreted as contact between the building material(s) such as concrete and surrounding materials with clustering at anomalies 5, 6,9 , and 10. Structures with SI of one are interpreted as box like structures which forms good solutions clustering at anomalies 2, 6, and 7. The SI of box for a magnetic source is not available in the literature, however using model study carried out in this research, the SI of box is estimated as one (1). Anomalies 1, 3, 4, and 8 (Fig. 14) produces good solution clustering for SI of two, therefore vertical cylinder like structure is expected at the mentioned points which are suspected to be the underground concrete pillars. At an index of 3 , few or no solution clustering is observed. From Fig. 14, a clue to the nature of the source is obtained by examining the solution clustering of estimated SI values of each feature.

\section{CONCLUSION}

A new technique based on Euler homogeneity relation that estimate background, horizontal coordinate $\left(\mathrm{x}_{0}\right.$ and $\left.\mathrm{y}_{0}\right)$, depth and structural index (SI) of gridded magnetic data is presented. Unlike the previous techniques, the present methodology involves the use of first order derivatives, the inversion process is independent of AS and it does not involve complex mathematical operations. The robust integrated filter that operates automatically and simultaneously assisted in the selection of valid solution in this methodology.

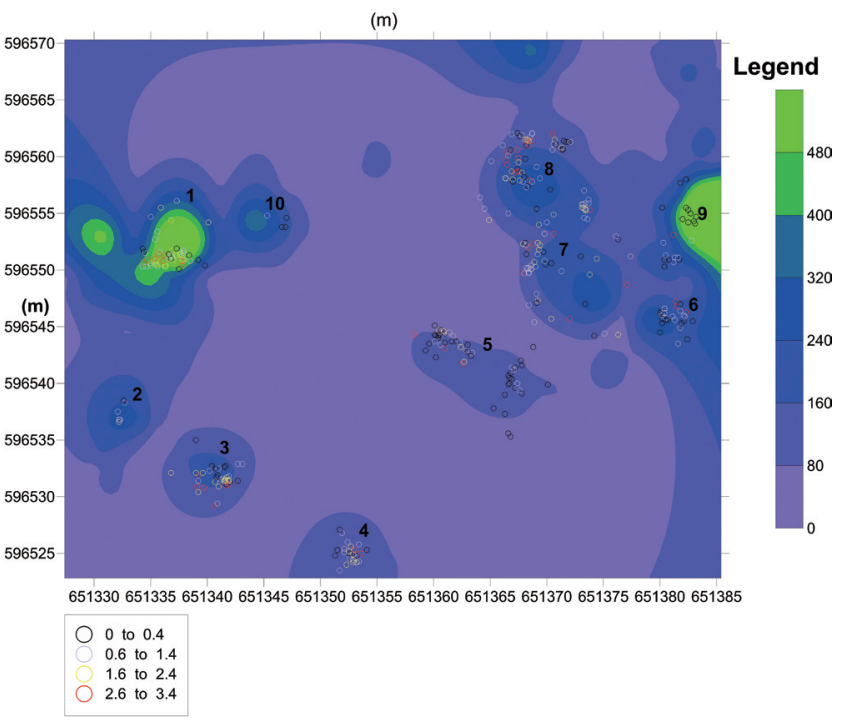

Fig. 14. SI solutions (application site) super imposed on AS $\left(\mathrm{nT} \mathrm{m}^{-1}\right)$. 
The source estimates are greatly improved through the use of the locations above the target's critical points indicated by analytic signal. The theoretical and field models study validates the effectiveness of this technique to be used in any location without reduction to the pole/equator or pseudo gravity. Empirically, the structural index of a box is found to be one (1), as indicated by the theoretical model studies. The technique is finally applied to investigate the remains of some metallic building materials that are interpreted to be located at the maximum depth of $9.4 \mathrm{~m}$. The present methodology provides reliable position estimates in all the tests carried out. It is fast means of magnetic data interpretation and easy to implement.

Acknowledgements The authors wish to acknowledge the support given by Near Surface Geophysics Group (NSGG) of the geological society of London located at Leicester University for the permission to use the field model data.

\section{REFERENCES}

Abedi, M., A. Gholami, G.-H. Norouzi, and N. Fathianpour, 2013: Fast inversion of magnetic data using Lanczos bidiagonalization method. J. Appl. Geophys., 90, 126137, doi: 10.1016/j.jappgeo.2013.01.008. [Link]

Adelusi, A. O., A. A. Akinlalu, and A. I. Nwachukwu, 2013: Integrated geophysical investigation for postconstruction studies of buildings around School of Science area, Federal University of Technology, Akure, Southwestern, Nigeria. Int. J. Phys. Sci., 8, 657-669, doi: 10.5897/ijps2012.0204. [Link]

Arisona, A., M. Nawawi, U. K. Nuraddeen, and M. Hamzah, 2016: A preliminary mineralogical evaluation study of natural asphalt rock characterization, southeast $\mathrm{Su}$ lawesi, Indonesia. Arab. J. Geosci., 9, doi: 10.1007/ s12517-015-2288-3. [Link]

Barbosa, V. C. F. and J. B. C. Silva, 2011: Reconstruction of geologic bodies in depth associated with a sedimentary basin using gravity and magnetic data. Geophys. Prospect., 59, 1021-1034, doi: 10.1111/j.13652478.2011.00997.x. [Link]

Bhattacharyya, B. K., 1964: Magnetic anomalies due to prism-shaped bodies with arbitrary polarization. Geophysics, 29, 517-531, doi: 10.1190/1.1439386. [Link]

Breiner, S., 1999: Applications Manual for Portable Magnetometers, Geomatrics, San Jose California USA. Available at ftp://geom.geometrics.com/pub/mag/Literature/ AMPM-OPT.PDF.

Chambers, J., R. Ogilvy, O. Kuras, J. Cripps, and P. Meldrum, 2002: 3D electrical imaging of known targets at a controlled environmental test site. Environ. Geol., 41, 690-704, doi: 10.1007/s00254-001-0452-4. [Link]

Chen, Q., Y. Dong, S. Cheng, L. Han, H. Xu, and H. Chen,
2014: Interpretation of fault system in the Tana Sag, Kenya, using edge recognition techniques and Euler deconvolution. J. Appl. Geophys., 109, 150-161, doi: 10.1016/j.jappgeo.2014.07.020. [Link]

Cooper, G. R. J., 2015: Using the analytic signal amplitude to determine the location and depth of thin dikes from magnetic data. Geophysics, 80, J1-J6, doi: 10.1190/ geo2014-0061.1. [Link]

Cooper, G. R. J. and R. C. Whitehead, 2016: Determining the distance to magnetic sources. Geophysics, 81, J25J34, doi: 10.1190/geo2015-0142.1. [Link]

FitzGerald, D., A. Reid, and P. McInerney, 2004: New discrimination techniques for Euler deconvolution. Comput. Geosci., 30, 461-469, doi: 10.1016/j.cageo.2004.03.006. [Link]

Florio, G., M. Fedi, and R. Pasteka, 2006: On the application of Euler deconvolution to the analytic signal. Geophysics, 71, L87-L93, doi: 10.1190/1.2360204. [Link]

Gerovska, D. and M. J. Araúzo-Bravo, 2003: Automatic interpretation of magnetic data based on $\mathrm{Eu}-$ ler deconvolution with unprescribed structural index. Comput. Geosci., 29, 949-960, doi: 10.1016/S00983004(03)00101-8. [Link]

Gerovska, D., M. J. Araúzo-Bravo, P. Stavrev, and K. Whaler, 2010: MaGSoundDST - 3D automatic inversion of magnetic and gravity data based on the differential similarity transform. Geophysics, 75, L25-L38, doi: 10.1190/1.3298619. [Link]

Haile, T. and A. Ayele, 2014: Electrical resistivity tomography and magnetic surveys: applications for building site characterization at Gubre, Wolkite University site, western Ethiopia. SINET: Ethiop. J. Sci., 37, 13-30.

Hassan, K., 1990: A summary of the Quaternary geology investigations in Seberang Prai, Pulau Pinang and Kuala Kurau. Geol. Soc. Malaysia Bull., 26, 47-53.

Hsu, S. K., 2002: Imaging magnetic sources using Euler's equation. Geophys. Prospect., 50, 15-25, doi: 10.1046/j.1365-2478.2001.00282.x. [Link]

John, R. C. F., 1965: Introduction to Calculus and Analysis, Vol. I, XXIII, 661.

Keating, P. and M. Pilkington, 2004: Euler deconvolution of the analytic signal and its application to magnetic interpretation. Geophys. Prospect., 52, 165-182, doi: 10.1111/j.1365-2478.2004.00408.x. [Link]

Khalil, A. E., M. Nawawi, M. H. Arifin, F. M. Abdullah, J. S. Kayode, and N. Usman, 2017: Soil Investigation at Wet World Hot Spring Complex for Future Development using Active Multichannel Analysis of Surface Waves. Sains Malaysia, 46, 537-543, doi: 10.17576/ jsm-2017-4604-04. [Link]

Levine, D. M., P. P. Ramsey, and R. K. Smidt, 2001: Applied Statistics for Engineers and Scientists: Using Microsoft Excel \& Minitab, Pearson.

Loke, M. H., J. E. Chambers, D. F. Rucker, O. Kuras, 
and P. B. Wilkinson, 2013: Recent developments in the direct-current geoelectrical imaging method. $J$. Appl. Geophys., 95, 135-156, doi: 10.1016/j.jappgeo.2013.02.017. [Link]

Marchetti, M., V. Sapia, and A. Settimi, 2013: Magnetic anomalies of steel drums: A review of the literature and research results of the INGV. Ann. Geophys., 56, R0108-R0119, doi: 10.4401/ag-6201. [Link]

Melo, F. F., V. C. F. Barbosa, L. Uieda, V. C. Oliveira Jr., and J. B. C. Silva, 2013: Estimating the nature and the horizontal and vertical positions of 3D magnetic sources using Euler deconvolution. Geophysics, 78, J87-J98, doi: 10.1190/geo2012-0515.1. [Link]

Mushayandebvu, M. F., V. Lesur, A. B. Reid, and J. D. Fairhead, 2004: Grid Euler deconvolution with constraints for 2D structures. Geophysics, 69, 489-496, doi: 10.1190/1.1707069. [Link]

Nabighian, M. N., 1972: The analytic signal of two-dimensional magnetic bodies with polygonal cross-section: Its properties and use for automated anomaly interpretation. Geophysics, 37, 507-517, doi: 10.1190/1.1440276. [Link]

Nordiana, M. M., S. Rosli, S. M. Mokhtar, N. M. M. Nawawi, and I. N. Azwin, 2012: Imaging subsurface characterization at Bukit Bunuh using 2D resistivity method: The effectiveness of enhancing horizontal resolution (EHR) technique. Int. J. Environ. Sci. Dev., 3, 569-573, doi: 10.7763/ijesd.2012.v3.287. [Link]

Oruç, B., 2010: Location and depth estimation of pointdipole and line of dipoles using analytic signals of the magnetic gradient tensor and magnitude of vector components. J. Appl. Geophys., 70, 27-37, doi: 10.1016/j. jappgeo.2009.10.002. [Link]

Oruç, B. and H. H. Selim, 2011: Interpretation of magnetic data in the Sinop area of Mid Black Sea, Turkey, using tilt derivative, Euler deconvolution, and discrete wavelet transform. J. Appl. Geophys., 74, 194-204, doi: 10.1016/j.jappgeo.2011.05.007. [Link]

Prezzi, C., M. J. Orgeira, H. Ostera, and C. A. Vásquez, 2005: Ground magnetic survey of a municipal solid waste landfill: Pilot study in Argentina. Environ. Geol., 47, 889-897, doi: 10.1007/s00254-004-1198-6. [Link]

Ravat, D., 1996: Analysis of the Euler method and its applicability in environmental magnetic investigations. J. Environ. Eng. Geophys., 1, 229-238, doi: 10.4133/ jeeg1.3.229. [Link]

Reid, A. B. and J. B. Thurston, 2014: The structural index in gravity and magnetic interpretation: Errors, uses, and abuses. Geophysics, 79, J61-J66, doi: 10.1190/ geo2013-0235.1. [Link]
Reid, A. B., J. M. Allsop, H. Granser, A. J. Millett, and I. W . Somerton, 1990: Magnetic interpretation in three dimensions using Euler deconvolution. Geophysics, 55, 80-91, doi: 10.1190/1.1442774. [Link]

Roest, W. R., J. Verhoef, and M. Pilkington, 1992: Magnetic interpretation using the 3-D analytic signal. Geophysics, 57, 116-125, doi: 10.1190/1.1443174. [Link]

Salem, A. and D. Ravat, 2003: A combined analytic signal and Euler method (AN-EUL) for automatic interpretation of magnetic data. Geophysics, 68, 1952-1961, doi: 10.1190/1.1635049. [Link]

Salem, A., D. Ravat, T. J. Gamey, and K. Ushijima, 2002: Analytic signal approach and its applicability in environmental magnetic investigations. J. Appl. Geophys., 49, 231-244, doi: 10.1016/S0926-9851(02)00125-8. [Link]

Salem, A., S. Williams, D. Fairhead, R. Smith, and D. Ravat, 2008: Interpretation of magnetic data using tilt-angle derivatives. Geophysics, 73, L1-L10, doi: 10.1190/1.2799992. [Link]

Shamsipour, P., M. Chouteau, and D. Marcotte, 2011: 3D stochastic inversion of magnetic data. J. Appl. Geophys., 73, 336-347, doi: 10.1016/j.jappgeo.2011.02.005. [Link]

Shamsipour, P., D. Marcotte, and M. Chouteau, 2012: 3D stochastic joint inversion of gravity and magnetic data. J. Appl. Geophys., 79, 27-37, doi: 10.1016/j.jappgeo.2011.12.012. [Link]

Stavrev, P. Y., 1997: Euler deconvolution using differential similarity transformations of gravity or magnetic anomalies. Geophys. Prospect., 45, 207-246, doi: 10.1046/j.1365-2478.1997.00331.x. [Link]

Tedla, G. E., M. van der Meijde, A. A. Nyblade, and F. D. van der Meer, 2011: A crustal thickness map of Africa derived from a global gravity field model using Euler deconvolution. Geophys. J. Int., 187, 1-9, doi: 10.1111/j.1365-246X.2011.05140.x. [Link]

Thompson,D.T., 1982: EULDPH: A new technique for making computer-assisted depth estimates from magnetic data. Geophysics, 47, 31-37, doi: 10.1190/1.1441278. [Link]

Ugalde, H. and W. A. Morris, 2010: Cluster analysis of Euler deconvolution solutions: New filtering techniques and geologic strike determination. Geophysics, 75, L61-L70, doi: 10.1190/1.3429997. [Link]

Yang, J., F. P. Agterberg, and Q. Cheng, 2015: A novel filtering technique for enhancing mineralization associated geochemical and geophysical anomalies. Comput. Geosci., 79, 94-104, doi: 10.1016/j.cageo.2015.03.011. [Link] 


\section{APPENDIX A}
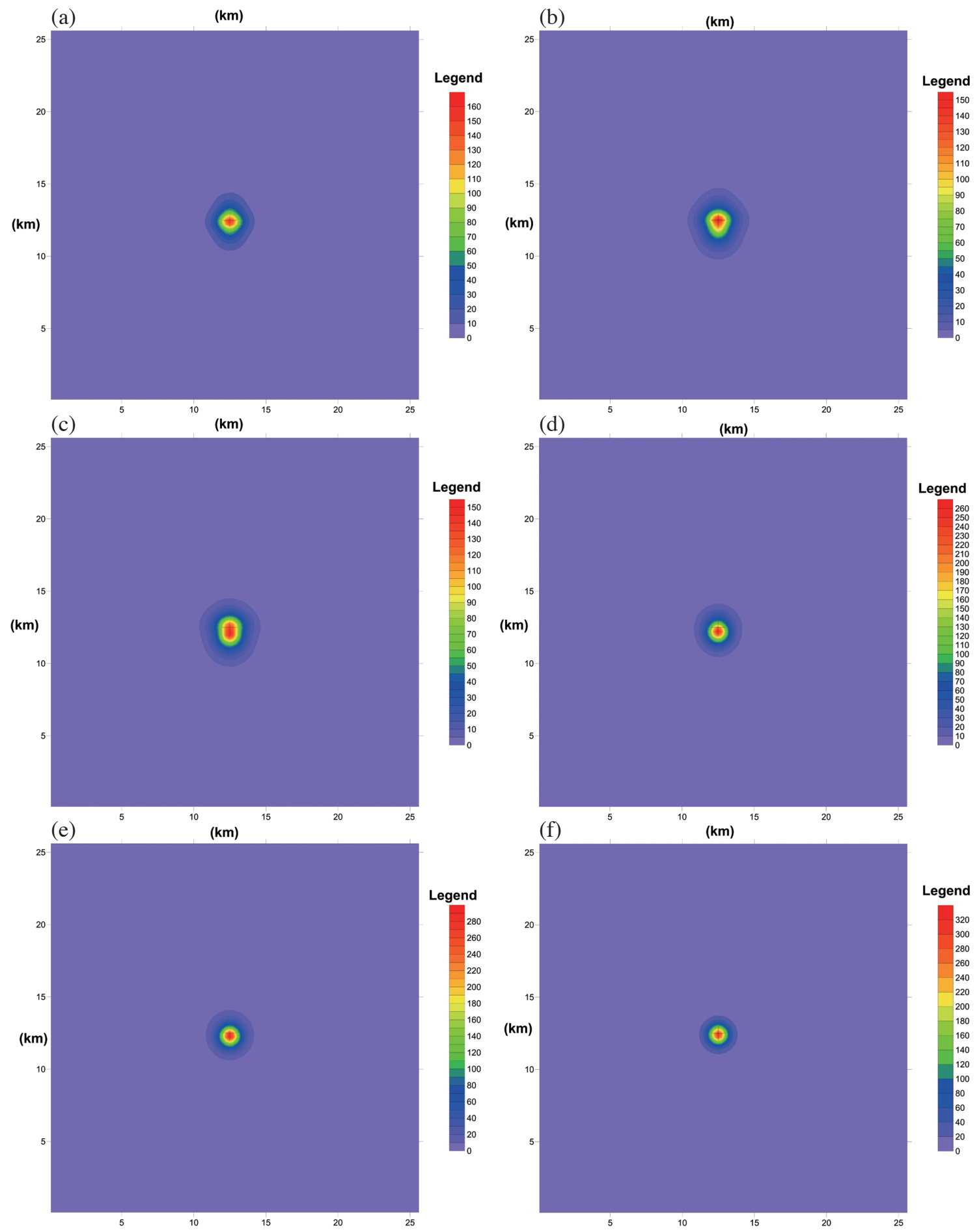

Fig. A1. AS (nT km ${ }^{-1}$ ) of total field for (a) $\mathrm{I}=0^{\circ}$, (b) $\mathrm{I}=15^{\circ}$, (c) $\mathrm{I}=30^{\circ}$, (d) $\mathrm{I}=65^{\circ}$, (e) $\mathrm{I}=75^{\circ}$, and (f) $\mathrm{I}=90^{\circ}$. 


\section{APPENDIX B}

(a)

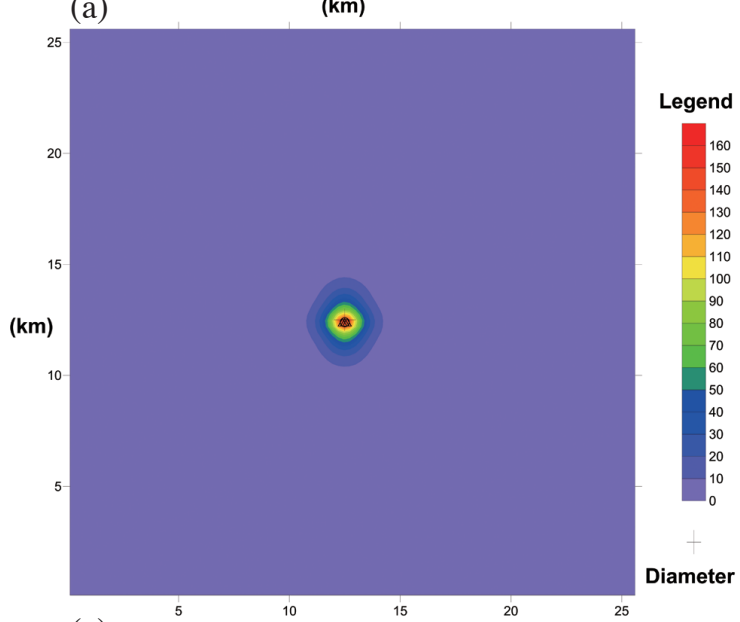

(c)

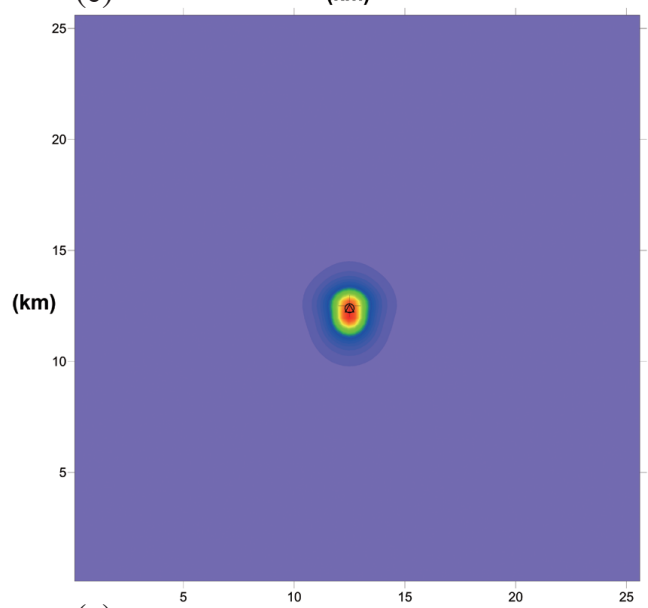

(e)

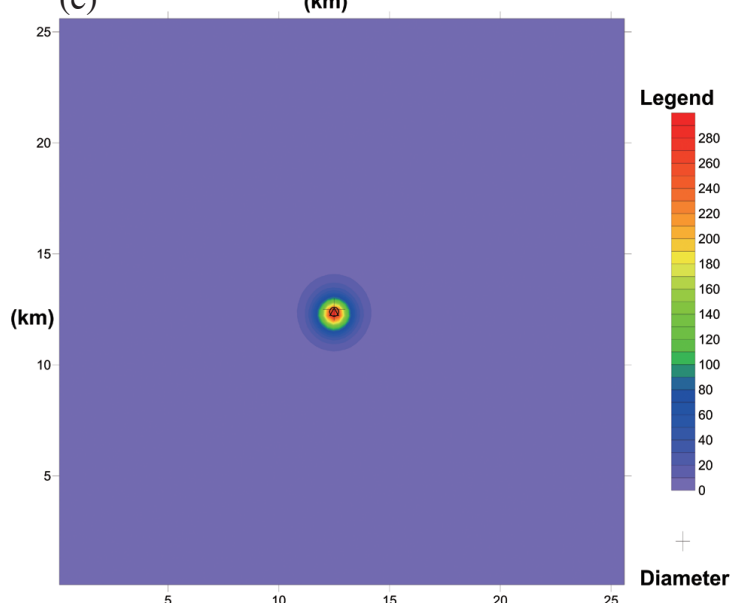

(b)
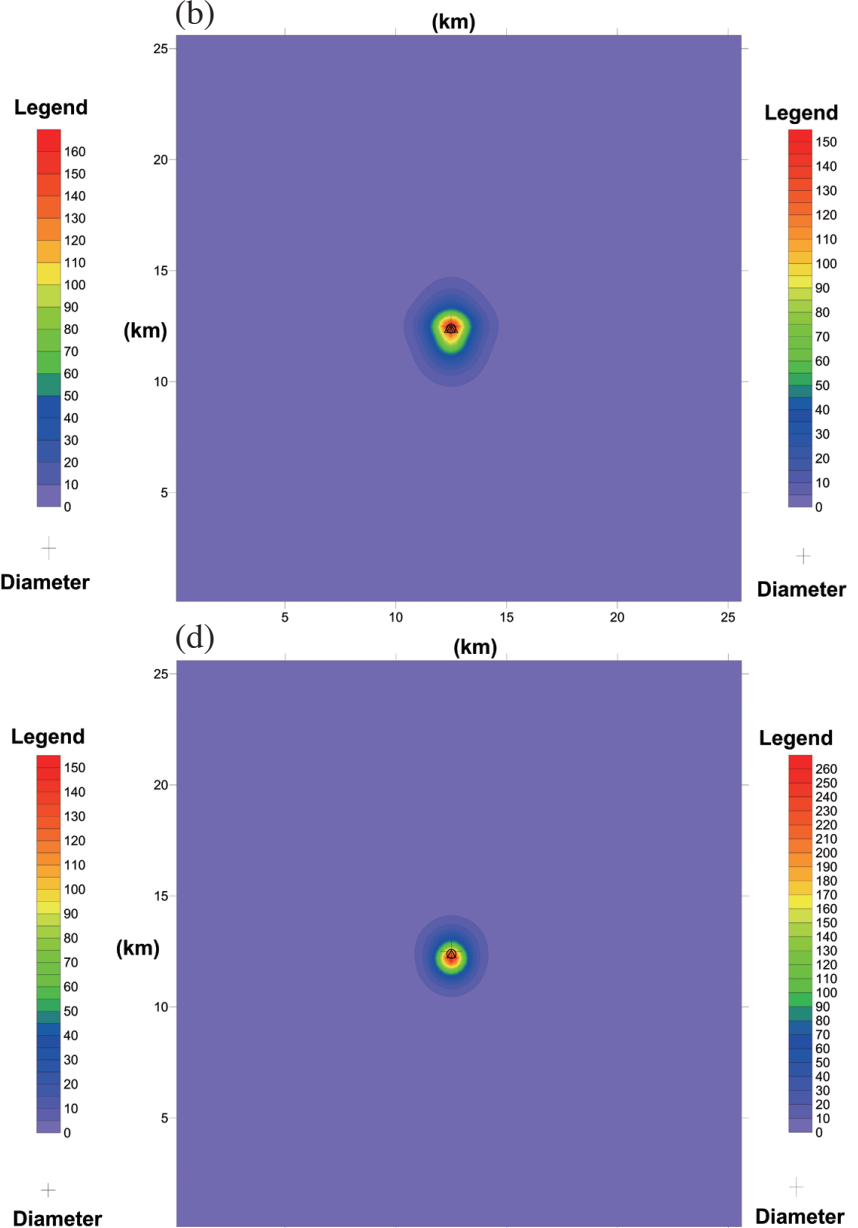

Diameter
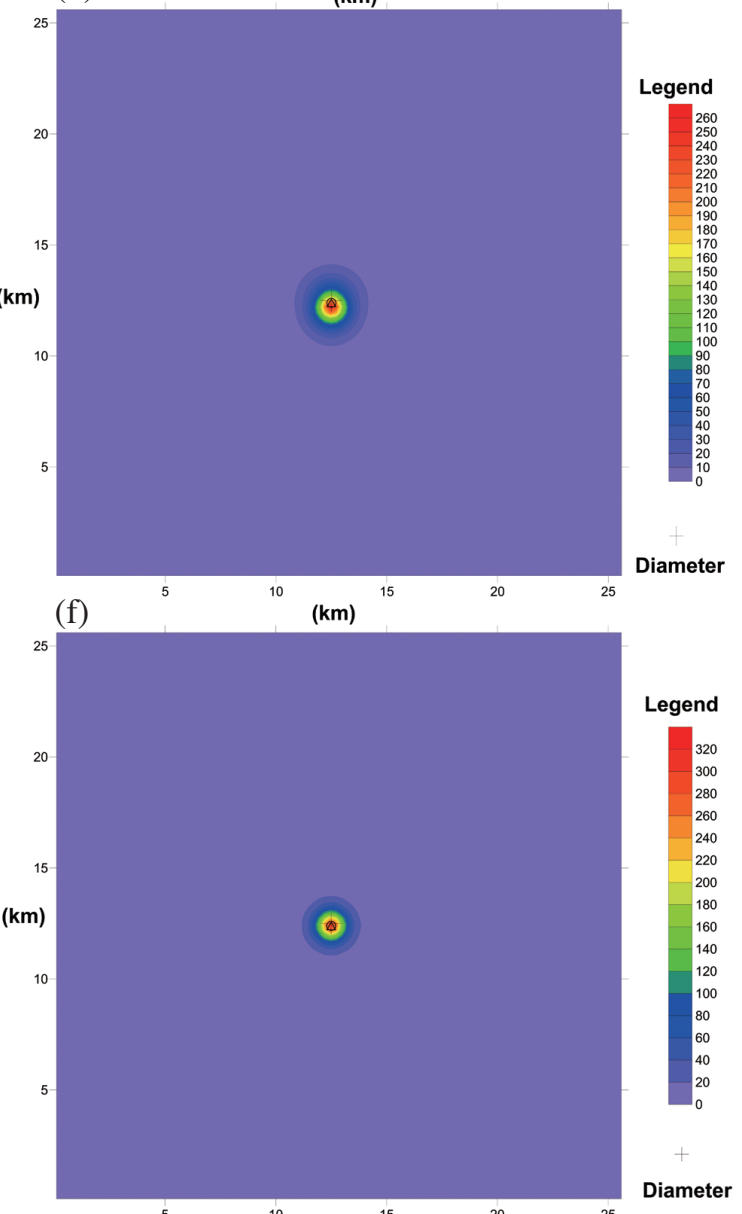

Fig. A2. Depth solutions super imposed on analytic signal $\left(n T \mathrm{~km}^{-1}\right)$ of total field for (a) $\mathrm{I}=0^{\circ}$, (b) $\mathrm{I}=15^{\circ}$, (c) $\mathrm{I}=30^{\circ}$, (d) $\mathrm{I}=65^{\circ}$, (e) $\mathrm{I}=75^{\circ}$, and (f) $\mathrm{I}=90^{\circ}$. 